\title{
Calcium and Lead Levels in the Biological Samples and Their Effect on the Biochemical Parameters of Indoor and Outdoor Workers of Five Zonal Areas of Coal Mining Field
}

\author{
Hassan Imran Afridi*, Qutubuddin Solangi, Tasneem Gul Kazi, Farah Naz Talpur, \\ Jameel Ahmed Baig, Ghulam Qadir Chanihoon, Ghulam Mustafa Channa
}

National Centre of Excellence in Analytical Chemistry, University of Sindh, Jamshoro, Pakistan

Email: ^hassanimranafridi@yahoo.com, ^hassan.afridi@usindh.edu.pk

How to cite this paper: Afridi, H.I., Solangi, Q., Kazi, T.G., Talpur, F.N., Baig, J.A., Chanihoon, G.Q. and Channa, G.M. (2021) Calcium and Lead Levels in the Biological Samples and Their Effect on the Biochemical Parameters of Indoor and Outdoor Workers of Five Zonal Areas of Coal Mining Field. American Journal of Analytical Chemistry, 12, 260-276. https://doi.org/10.4236/ajac.2021.126016

Received: May 14, 2021

Accepted: June 22, 2021

Published: June 25, 2021

Copyright $\odot 2021$ by author(s) and Scientific Research Publishing Inc. This work is licensed under the Creative Commons Attribution International License (CC BY 4.0).

http://creativecommons.org/licenses/by/4.0/ (c) (i) Open Access

\begin{abstract}
Workers of the Lakhra coal mining Sindh Pakistan were affected by a multifactorial exposure of heavy metals. The prevalence of lead $(\mathrm{Pb})$ exposures in work-related symptoms among workers of indoor and outdoor mining of Lakhra coal mining was evaluated in detail. The biological samples (scalp hair and blood) of 270 workers of Lakhra coal mining \{official and control subjects\} (indoor and outdoor) 18 to 55 years age group and 70 referent subjects of same age-groups were examined. The biological samples (blood and scalp hair) of workers of Lakhra coal mining and referent subjects were analyzed for calcium $(\mathrm{Ca})$ and lead $(\mathrm{Pb})$. Flame atomic absorption spectrometry was applied for the determination of the $\mathrm{Ca}$ in digested samples of studied subjects by the microwave oven whereas, the $\mathrm{Pb}$ contents were measured by electrothermal atomic absorption spectrometry. The validity of the methodology was checked by using the certified human hair material (BCR 397) and lyophilized human blood (Clincheck). The results indicated the higher contents of $\mathrm{Pb}$ in biological samples of indoor and outdoor mining workers than referents. However, the levels of $\mathrm{Ca}$ were found to be lower in indoor and outdoor mining workers than those of referents. It can be concluded that immediate action should be taken by recommended authorities to improve the ventilation and hygiene practices inside the industries, mines, and other workplaces.
\end{abstract}

\section{Keywords}

Essential Elements, Toxic Elements, Biological Samples, Lakhra Coal Mining, Atomic Absorption Spectrophotometry 


\section{Introduction}

Coal is a nonrenewable fossil fuel that is combusted and used to generate electricity. Mining techniques and combustion are both dangerous to miners and hazardous to the environment [1]. Coal is a black or brownish-black sedimentary rock that can be burned for fuel and used to generate electricity. It is composed mostly of carbon and hydrocarbons, which contain energy that can be released through combustion (burning) [2].

Coal mining is the process of extracting coal from the ground. Coal mining is the process of extracting coal from the ground. Coal mining has had many developments over the recent years, from the early days of men tunneling, digging, and manually extracting the coal on carts to large open cut and long wall mines [1]. Mining at this scale requires the use of draglines, trucks, conveyors, hydraulic jacks and shearers. The coal mining industry has a long history of significant negative environmental impacts on local ecosystems, health impacts on local communities and workers, and contributes heavily to the global environmental crises, such as poor air quality and climate change. For these reasons, coal has been one of the first fossil fuels to be phased out of various parts of the global energy economy [2].

Mining exercises may have perceived to be a pinned impact on our environment. These impacts may include the disturbance in the structure of residual soil and its profile. Moreover, these activities may also be associated with potential contaminating impacts on vegetation, plantation, and enhancing the levels of trace and toxic metals in nearby running water streams [1].

The coal industry has been centering on the consideration of the researchers. Coal mining is perceived to be many toxic materials disseminated during surface mining. These materials may include arsenic, lead, and mercury. These elements may spread into the air when the coal is burnt. Moreover, coal-burning may produce particulates associated with severe health consequences. Besides these toxic elements, coal-burning may release a large amount of $\mathrm{CO}_{2}$ to increase the green-house effect [2].

Furthermore, these activities may have dangerous effects on the ecosystem including the loss of biodiversity, the creation of sinkholes, contamination of natural water sources, and air [3].

Calcium $(\mathrm{Ca})$ is necessary for human beings in many perspectives, including the formation of strong bones and teeth, blood controlling mechanisms, to regulate muscles and the nervous system of the human body. Absorbed Ca stored in the human skeleton [4]. Extra absorbed Ca expelled out from the body through urine and skin in the form of sweat and feces. The normal level of $\mathrm{Ca}$ in nearly born baby is about 0.8 percent of the body weight whilst in adults it is about 1.7 percent of body weight (Afridi et al., 2015). Overall, our bones contain a total 99 percent $\mathrm{Ca}$ of the body, where it represents $39 \%$ of the complete body bone mineral substance [5]. The Ca levels in neurodegeneration sick person were altogether lower than controls subjects, which may propose a pathogenic effect on T-cell capacity and demyelination [6]. Due to low intake of essential 
elements, likes $\mathrm{Ca}$ and $\mathrm{Mg}$, whereas greater disclosure of poisonous components likes $\mathrm{Cd}$ and $\mathrm{Pb}$, causes neuronal degeneration and demise [6]. Toxic elements exposure is widely known to workers who are working in the industry involving the use of materials. These materials then bind to bio-active sites in the biological system and alter the metabolism of various biological functions. If the worker is exposed to higher doses than the daily prescribed limit. With the exposure to these elements, the workers are also exposed to fumes, toxic gases, and dust that are known to have short term effects and long-term effects as well [7].

The toxic metals can also impair the normal function of essential and trace metals in the enzymatic processes. The toxic metals can be replacing the nutritional minerals in the enzymes and inactive to them. However, higher amounts of essential vitamins and minerals may help our biological systems to get rid of an excess concentration of toxic elements (Kazi et al., 2008). Melanosomes bind metal ions according to volume and atomic weight. Heavy metals can effectively compete to same binding sites as foreign ions to replace previously bound metals [8]. However, these bonded heavy metals cannot easily manageable to displacement [8]. The $\mathrm{Pb}$ and cadmium neurotoxicity takes place through the creation of lipid peroxidation and hindrance of superoxide dismutase [9]. It accounted that the contents of $\mathrm{Pb}$ are perceived to connect with some $\mathrm{Ca}$ regulated enzymes that incorporate protein kinase $\mathrm{C}$ making oxidative harm and causative neurodegeneration [10].

The casualty from $\mathrm{Pb}$ harming is typically associated with level of $\mathrm{Pb}$ in blood $(>100 \mu \mathrm{g} / \mathrm{dL})[10]$. Even though blood $\mathrm{Pb}$ concentrations of $10 \mu \mathrm{g} / \mathrm{dL}$ can adversely influence the hematopoietic CNS framework and kidney. The admission of dangerous components, for example, $\mathrm{Pd}, \mathrm{Mn}$, and $\mathrm{Cd}$ in coal mining zones laborers may promote diabetic Mellitus, hypertensive and atherosclerosis also a neurological issue, for example, Parkinson, dementia and different infections by expanding oxidative worry because of the lack of basic minerals like $\mathrm{Zn}, \mathrm{Ca}, \mathrm{Mg}$, etc. [11]. To keep check and balance of the exposure of $\mathrm{Pb}$ to workers the biological samples to urine, blood, scalp hair and plasma are needed to be analyzed [12].

This analysis may help us to recommend certain measures to mines and industries by which they may reduce the escape of higher $\mathrm{Pb}$ concentrations. Atomic absorption spectrometry is well renowned for such analysis due to being sensitive and precise quantification technique [12]. Considering hair is made up of dead protein cells known to have a record of exposed elements for a long time than those of urine and blood specimens. Therefore, hair samples are considered as best biomarkers [13].

The purpose of this research was to investigate the essential trace (calcium) and toxic elements $(\mathrm{Pb})$ in biological (blood and scalp hair) samples of long-term exposure indoor and outdoor workers \{official and control subjects\} of five different zones of the coal mining industry. The obtained results compared with those of the same age group healthy persons not exposed to any industrial environmental pollution. 


\section{Material and Methods}

\subsection{Recruitment}

For the initiation of this study a prior permission was obtained from ethical review committee of University of Sindh, Jamshoro-Pakistan.

\subsection{Apparatus}

Electrothermal atomic absorption spectrometer (ETAAS) was utilized for $\mathrm{Pb}$ analysis, whilst flame atomic absorption spectrometer (FAAS) mode was used for the detection of $\mathrm{Ca}$. The instrument conditions are given in Table 1. The absorbance signals generated by the equipment were integrated and computed for use. Domestic micro-wave oven (PMO23) Pel with $900 \mathrm{~W}$ heating power was used for the digestion of samples. Poly-tetra-fluro-ethylene (PTFE) bottles, washed with acid, were used for sample storage and sample preparation. Complex standard and reagents blanks were analyzed in parallel and required corrections were made.

\subsection{Reagents and Glassware}

Water used during processes was ultra-pure transfused through Millipore (Mili-Q USA). E. Merck-Germany, produces analytical grade chemicals including hydrogen per oxide and nitric acid were used. All the samples were tested for metal contaminations before use. Fluka Kamica (Buchs, Switzerland) certificated 1000 ppm standard solutions of $\mathrm{Ca}$ and $\mathrm{Pb}$ were used. Serial dilution of Working standard (stock) solutions were made using $\mathrm{HNO}_{3}\left(0.2 \mathrm{~mol} \cdot \mathrm{L}^{-1}\right)$. The produced solutions were refrigerated at $4^{\circ} \mathrm{C}$ for further analysis in polyethylene bottles. To reach sensitive and selective method, certified reference materials (CRMs) of human hair BCR 397 (Brussels, Belgium) and Clinchek ${ }^{\circledR}$ Control lypholized human blood (Germany Munich, Recipe) were bought. Plastic materials and apparatus were dipped in $2 \mathrm{~mol} \cdot \mathrm{L}^{-1} \mathrm{HNO}_{3}$ for twenty-four hours followed by washing and rinsing with Mili-Q'd water.

Table 1. Measurement conditions for electrothermal atomization AAS 700.

\begin{tabular}{ccc}
\hline Parameters & Lead & Calcium \\
\hline Lamp current $(\mathrm{mA})$ & 7.5 & 7.5 \\
Wave length (nm) & 283.3 & 422.7 \\
Slit width $(\mathrm{nm})$ & 1.3 & 0.7 \\
Drying Temp $\left({ }^{\circ} \mathrm{C}\right) / \mathrm{ramp}$ hold $(\mathrm{s})$ & $140 / 15 / 5$ & \\
Ashing Temp $\left({ }^{\circ} \mathrm{C}\right) / \mathrm{ramp}$ hold $(\mathrm{s})$ & $700 / 10 / 20$ & Burner height $(\mathrm{mm}) 12.5$ \\
Atomization Temp $\left({ }^{\circ} \mathrm{C}\right) / \mathrm{ramp}$ hold $(\mathrm{s})$ & $1800 / 0 / 5$. & Oxidant (Air) L-min ${ }^{-1} 17.0$ \\
Cleaning Temp $\left({ }^{\circ} \mathrm{C}\right) /$ ramp hold $(\mathrm{s})$ & $2600 / 1 / 3$ & Fuel (Acetylene) \\
Chemical Modifier & $15 \mu \mathrm{gg}\left(\mathrm{NO}_{3}\right)_{2} 2.0$ \\
\hline
\end{tabular}

Sample volume $(10 \mu \mathrm{l})$, Cuvette $=$ Cup, Carrier gas $=(200 \mathrm{ml} / \mathrm{min})$, Background correction $(\mathrm{D} 2 \mathrm{Lamp})$ used for all elements. 


\subsection{Study Population}

The current study population was from two age groups, adults (18 to 35 years) and old aged (36 to 55 years) in the period of March 2019-August 2019 (in between six months) randomly. The entire population was of males and they were also provided with consent form and additional form for their eating, physical and medical information. For comparative study, referent population, comprising adults and old aged of same age groups were chosen from non-industrial area, who had no prior occupational exposure.

In studied coal mining industry, there are five different sub industrial zones. In these sub industrial zones, there are two main areas in Coal mining, namely, indoor mining area and outdoor mining area. Most of the indoor and outdoor workers took part in average of 48 hours of work per week. Some out-door workers took part in overtime for extra money, making total of 12 hours of work per day. The selected sample population was working in the mine for $10-30$ years prior to their sampling day. All population members were examined systematically prior to sample collection. The demographical data of sampling is given in Table 2. An in-depth medical examination was carried out for each population member with the help from on-site toxicologists and epidemiologists with the collaboration of university staff and the political health authorities. A consent form from each participating mine worker was obtained mentioning the permission for the sample collection and analysis of those samples. A detailed questionnaire concerning ethnic origin, physical data, exposure time, details about health, dietary habit, job classification, age, smoking habits, and duration of employment was also provided to each worker for detailed knowledge about them. The physical checkup included height, blood pressure, weight and other bio-chemical data of the participants. There were no statistically significant differences $(p<0.05)$ between all coal mining workers regarding to height and weight (Table 3). Rules set by ILO-1999 (International Labor Organization) for the immediate elimination of all form of child labor were followed by all the works in this study [14]. Usually many mining factories hire younger boys under 18 because it saves them a lot of money as well all the nascence produced by adult labor, whereas, Lakhra coal mine follows the ILO-199 rule (as prescribed

Table 2. The number of subjects as control and coal mining workers.

\begin{tabular}{cccccccc}
\hline \multirow{2}{*}{$\begin{array}{c}\text { Mining Areas } \\
\text { workers }\end{array}$} & $\begin{array}{c}\text { Age } \\
\text { groups }\end{array}$ & Referents & \multicolumn{6}{c}{ Workers } \\
\cline { 4 - 8 } & & PMDC & LCDC & ICD & HCM & BCM \\
\hline Indoor Workers & $18-35$ & ----- & 17 & 18 & 15 & 13 & 15 \\
& $36-55$ & $-\cdots---$ & 13 & 09 & 14 & 10 & 12 \\
Outdoor Workers & $18-35$ & 29 & 19 & 09 & 21 & 07 & 18 \\
& $36-55$ & 28 & 15 & 08 & 17 & 05 & 15 \\
Total & & 57 & 64 & 44 & 67 & 35 & 60 \\
\hline
\end{tabular}

Keywords: Lakhra coal development company (LCDC), Hashim coal mine (HCM), Indus coal mine (ICM), Bismillah coal mine (BCM), and Pakistan mine development company (PMDC). 
Table 3. Clinical and biochemical characteristics of male coal mining workers, working in five sub divisions of Lakhra coal mining area.

\begin{tabular}{|c|c|c|c|c|c|c|c|}
\hline & \multirow{2}{*}{ Referents } & \multicolumn{5}{|c|}{ Workers } & \multirow{2}{*}{$\begin{array}{l}\text { Normal } \\
\text { range }\end{array}$} \\
\hline & & PMDC & LCDC & ICD & $\mathrm{HCM}$ & $\mathrm{BCM}$ & \\
\hline \multicolumn{8}{|c|}{ Indoor Workers } \\
\hline \multicolumn{8}{|c|}{$18-35$} \\
\hline Serum ferritin $(\mathrm{mg} / \mathrm{l})$ & & $27.6 \pm 3.34$ & $24.6 \pm 1.58$ & $22.8 \pm 1.12$ & $26.3 \pm 3.03$ & $24.7 \pm 2.11$ & $\geq 30$ \\
\hline Hemoglobin (g/dl) & & $12.1 \pm 0.55$ & $10.8 \pm 0.32$ & $12.5 \pm 0.58$ & $11.3 \pm 0.34$ & $10.8 \pm 0.49$ & $11.5-16.5$ \\
\hline Hematocrit (\%) & & $36.8 \pm 2.81$ & $33.4 \pm 2.37$ & $31.2 \pm 1.85$ & $35.0 \pm 1.97$ & $33.0 \pm 1.89$ & $35-55$ \\
\hline Red blood count $\left(\mathrm{M} / \mathrm{mm}^{3}\right)$ & & $3.26 \pm 0.38$ & $3.21 \pm 0.36$ & $2.99 \pm 0.27$ & $3.17 \pm 0.26$ & $3.16 \pm 0.13$ & $3.5-5.5$ \\
\hline Systolic blood pressure (mm Hg) & & $130 \pm 4.09$ & $135 \pm 5.04$ & $138 \pm 7.52$ & $147 \pm 6.21$ & $153 \pm 6.52$ & \\
\hline Diastolic blood pressure $(\mathrm{mm} \mathrm{Hg})$ & & $89.1 \pm 3.56$ & $91.2 \pm 2.56$ & $90.9 \pm 2.68$ & $96.9 \pm 3.59$ & $93.2 \pm 2.93$ & $80-120$ \\
\hline $\mathrm{ESR}(\mathrm{mm} / 1 \mathrm{hr})$ & & $34.2 \pm 2.75$ & $33.9 \pm 3.92$ & $33.8 \pm 1.65$ & $35.2 \pm 2.39$ & $32.4 \pm 1.56$ & \\
\hline Creatinine clearance $(\mathrm{mL} / \mathrm{min})$ & & $68.1 \pm 4.03$ & $57.9 \pm 4.17$ & $52.7 \pm 4.21$ & $53.9 \pm 7.14$ & $51.6 \pm 4.51$ & \\
\hline $\begin{array}{l}\text { Urinary } \mathrm{N} \text {-acetyl-beta-glucosaminidase } \\
\text { (NAG) (IU/L) }\end{array}$ & & $24.6 \pm 0.73$ & $25.4 \pm 1.33$ & $26.1 \pm 1.30$ & $24.2 \pm 1.56$ & $25.3 \pm 0.33$ & \\
\hline \multicolumn{8}{|c|}{$36-55$} \\
\hline Serum ferritin $(\mathrm{mg} / \mathrm{l}$ & & $27.2 \pm 1.99$ & $23.0 \pm 3.41$ & $21.5 \pm 1.91$ & $23.6 \pm 1.14$ & $23.0 \pm 0.95$ & $\geq 30$ \\
\hline Hemoglobin (g/dl) & & $10.4 \pm 0.42$ & $9.2 \pm 0.35$ & $11.0 \pm 0.21$ & $10.3 \pm 0.31$ & $9.64 \pm 0.35$ & $11.5-16.5$ \\
\hline Hematocrit (\%) & & $36.8 \pm 3.47$ & $36.0 \pm 2.06$ & $33.2 \pm 2.80$ & $35.7 \pm 2.05$ & $36.50 \pm 1.32$ & $35-55$ \\
\hline Red blood count $\left(\mathrm{M} / \mathrm{mm}^{3}\right)$ & & $3.15 \pm 0.22$ & $3.26 \pm 0.12$ & $3.17 \pm 0.37$ & $3.02 \pm 0.18$ & $3.03 \pm 0.08$ & $3.5-5.5$ \\
\hline Systolic blood pressure (mm Hg) & & $123 \pm 6.74$ & $119 \pm 7.33$ & $128 \pm 3.60$ & $131 \pm 6.36$ & $135 \pm 5.23$ & $80 \quad 120$ \\
\hline Diastolic blood pressure $(\mathrm{mm} \mathrm{Hg})$ & & $81.8 \pm 1.99$ & $82.9 \pm 2.29$ & $82.8 \pm 1.69$ & $83.5 \pm 1.24$ & $84.2 \pm 1.48$ & \\
\hline $\operatorname{ESR}(\mathrm{mm} / 1 \mathrm{hr})$ & & $34.5 \pm 2.87$ & $36.1 \pm 3.05$ & $34.9 \pm 1.84$ & $36.4 \pm 2.28$ & $34.1 \pm 2.06$ & \\
\hline Creatinine clearance (mL/min) & & $71.2 \pm 8.36$ & $59.2 \pm 4.44$ & $55.1 \pm 6.99$ & $55.3 \pm 5.76$ & $51.1 \pm 5.37$ & \\
\hline $\begin{array}{l}\text { Urinary N-cetyl -eta-lucosaminidase } \\
\text { (NAG) (IU/L) }\end{array}$ & & $27.7 \pm 0.99$ & $25.7 \pm 2.89$ & $28.6 \pm 2.04$ & $27.8 \pm 1.90$ & $27.0 \pm 0.72$ & \\
\hline \multicolumn{8}{|c|}{ Out door } \\
\hline \multicolumn{8}{|c|}{$18-35$} \\
\hline Serum ferritin $(\mathrm{mg} / \mathrm{l})$ & $43.4 \pm 3.27$ & $25.9 \pm 2.64$ & $22.8 \pm 0.67$ & $22.0 \pm 1.20$ & $23.6 \pm 1.97$ & $23.8 \pm 1.04$ & $\geq 30$ \\
\hline Hemoglobin (g/dl) & $13.7 \pm 0.53$ & $9.65 \pm 0.35$ & $8.81 \pm 0.24$ & $10.3 \pm 0.21$ & $9.62 \pm 0.28$ & $9.1 \pm 0.27$ & $11.5-16.5$ \\
\hline Hematocrit (\%) & $48.7 \pm 2.36$ & $34.7 \pm 1.81$ & $32.5 \pm 1.52$ & $28.8 \pm 1.17$ & $33.2 \pm 0.60$ & $33.2 \pm 1.15$ & $35-55$ \\
\hline Red blood count $\left(\mathrm{M} / \mathrm{mm}^{3}\right)$ & $4.35 \pm 0.41$ & $3.24 \pm 0.29$ & $3.16 \pm 0.18$ & $3.28 \pm 0.31$ & $3.09 \pm 0.16$ & $3.09 \pm 0.12$ & $3.5-5.5$ \\
\hline Systolic blood pressure (mm Hg) & $115 \pm 3.37$ & $124 \pm 3.71$ & $118 \pm 4.82$ & $128 \pm 7.66$ & $129 \pm 7.70$ & $133 \pm 4.67$ & \\
\hline Diastolic blood pressure (mm Hg) & $77.0 \pm 2.34$ & $81.1 \pm 1.65$ & $83.2 \pm 1.76$ & $82.9 \pm 2.26$ & $83.0 \pm 0.66$ & $84.7 \pm 1.06$ & $80-120$ \\
\hline ESR $(\mathrm{mm} / 1 \mathrm{hr})$ & $8.57 \pm 0.42$ & $18.3 \pm 1.10$ & $15.8 \pm 0.67$ & $16.9 \pm 0.85$ & $16.9 \pm 1.16$ & $17.4 \pm 1.97$ & \\
\hline Creatinine clearance $(\mathrm{mL} / \mathrm{min})$ & $86.1 \pm 6.82$ & $42.0 \pm 7.55$ & $37.3 \pm 4.55$ & $38.0 \pm 6.28$ & $36.1 \pm 5.28$ & $38.7 \pm 2.62$ & \\
\hline $\begin{array}{l}\text { Urinary N-acetyl-beta-glucosaminidase } \\
\text { (NAG) (IU/L) }\end{array}$ & $3.45 \pm 0.39$ & $15.4 \pm 1.88$ & $14.1 \pm 0.88$ & $12.86 \pm 1.17$ & $13.8 \pm 2.63$ & $13.5 \pm 1.74$ & \\
\hline
\end{tabular}




\section{Continued}

\begin{tabular}{|c|c|c|c|c|c|c|c|}
\hline \multicolumn{8}{|c|}{$36-55$} \\
\hline Serum ferritin (mg/l) & $43.2 \pm 2.54$ & $28.3 \pm 1.64$ & $25.7 \pm 2.15$ & $27.8 \pm 1.07$ & $27.1 \pm 1.20$ & $27.8 \pm 1.48$ & $\geq 30$ \\
\hline Hemoglobin (g/dl) & $12.4 \pm 0.93$ & $8.35 \pm 0.48$ & $7.93 \pm 0.72$ & $7.70 \pm 0.75$ & $7.55 \pm 0.48$ & $7.16 \pm 0.64$ & $11.5-16.5$ \\
\hline Hematocrit (\%) & $47.3 \pm 1.21$ & $35.7 \pm 1.00$ & $34.1 \pm 0.50$ & $34.1 \pm 1.37$ & $32.9 \pm 1.98$ & $31.1 \pm 1.15$ & $35-55$ \\
\hline Red blood count $\left(\mathrm{M} / \mathrm{mm}^{3}\right)$ & $4.18 \pm 0.57$ & $3.24 \pm 0.60$ & $2.89 \pm 0.58$ & $2.81 \pm 0.33$ & $3.06 \pm 0.81$ & $3.06 \pm 0.37$ & $3.5-5.5$ \\
\hline Systolic blood pressure (mm Hg) & $122 \pm 8.95$ & $137 \pm 7.46$ & $128 \pm 6.89$ & $139 \pm 7.92$ & $136 \pm 7.72$ & $138 \pm 8.97$ & 80 \\
\hline Diastolic blood pressure $(\mathrm{mm} \mathrm{Hg})$ & $84.7 \pm 4.30$ & $93.2 \pm 3.32$ & $95.9 \pm 4.14$ & $92.7 \pm 5.33$ & $93.8 \pm 3.30$ & $91.9 \pm 5.72$ & \\
\hline ESR $(\mathrm{mm} / 1 \mathrm{hr})$ & $10.3 \pm 1.11$ & $23.3 \pm 2.37$ & $22.8 \pm 2.51$ & $24.0 \pm 0.62$ & $23.6 \pm 1.62$ & $21.2 \pm 3.23$ & \\
\hline Creatinine clearance (mL/min) & $110 \pm 11.0$ & $34.1 \pm 3.74$ & $31.1 \pm 6.55$ & $33.8 \pm 2.83$ & $33.3 \pm 4.88$ & $32.6 \pm 3.23$ & \\
\hline $\begin{array}{l}\text { Urinary N-cetyl-eta-lucosaminidase } \\
\text { (NAG) (IU/L) }\end{array}$ & $5.07 \pm 0.54$ & $16.5 \pm 1.84$ & $15.30 \pm 1.04$ & $14.6 \pm 1.70$ & $15.7 \pm 1.09$ & $15.3 \pm 2.16$ & \\
\hline
\end{tabular}

Keywords: Lakhra coal development company (LCDC), Hashim coal mine (HCM), Indus coal mine (ICM), Bismillah coal mine (BCM), and Pakistan mine development company (PMDC).

above). It is another fact that none of the labors were provided with personal protective equipment including safety shoes, safety glasses and goggles.

\subsection{Health Consequence of Subjects Working in Both Workshops}

Major effects due to exposure to high concentrations of lead were different physiological disorders (Table 1). It was reported that the health of all the workers, after medical examination, was not up to standard. $65 \%$ of the workers claimed to have gestor problems. Whereas, they had kidney and body ache issues. And $60 \%$ of the workers had headaches. The workers also had skin issues like rashes and spots on their skins.

\subsection{Sample Collection}

\subsubsection{Blood Sample Collection}

Aseptically blood was drawn from each volunteers' veins, with the help of a syringe. This process of drying blood was performed by a registered male nurse, with the help of $5 \mathrm{ml}$ sterile-one time use only, syringe. Area of puncture was cleaned with the help of alcohol swab-containing zero elements, sealed in a plastic covering. This type of alcohol swab was chosen only to avoid any type of infection and contamination. BD (Oxford, UK) vacutainer-(Trace Element tube with potassium-EDTA) was used for the collection of blood samples to be analyzed for trace elements. Before the collection of $5 \mathrm{ml}$ of blood sample, each volunteer was advised to fast overnight. Sample tubes were kept away from direct sunlight and container tubes were folded with $\mathrm{Al}$ foil to avoid any possible sunlight interaction with blood samples. The collected samples, after centrifugation, were refrigerated at $-20^{\circ} \mathrm{C}$ for further analysis.

\subsubsection{Scalp Hair Sample Collection}

Stainless steel scissors were used for the collection of hair samples of about $0.5 \mathrm{~g}$ (0.5 $-2.0 \mathrm{~cm}$ long) from each diseased and healthy participant. The scissors were 
thoroughly washed and cleaned with alcohol swab before and after cutting hair of each participant. Hair samples were collected from the back of the head and stored in sterile plastic bags. After collection of samples each bag was marked with confidential identifier number for each participant. These plastic bags were attached with questioner provided to each volunteer and were stored for digestion and further analysis.

\subsection{Microwave-Assisted (MW) Acid Digestion Method}

Duplicates of each sample were prepared for elemental analysis with the help of microwave oven-based digestion method. As for the certificated reference materials (human hair and blood), six replicate samples were prepared. Digestion was done by mixing $200 \mathrm{mg}$ of hair samples and $0.2 \mathrm{~mL}$ of blood sample with $1 \mathrm{~mL}$ of freshly prepared $\mathrm{H}_{2} \mathrm{O}_{2}-\mathrm{HNO}_{3}$ mixture (1:2, v/v) in PTFE flask, for each sample. This mixture in flask was then placed in MW oven followed by 3 min expose to microwaves at the power of $950 \mathrm{MW}$, until complete sample digestion was achieved. The flask containing digested samples were allowed to reach room temperature and diluted with Mili-Q water to reach final volume mark of $10 \mathrm{~mL}$. These samples were than analyzed for elements using by AAS. Same procedure was followed for the preparation of blank samples.

\subsection{Data and Statistical Analyses}

Excel X state and Minitab softwares were used for the statistical analysis of data. The reliability of method was found to be best in accord with certified values of elements, $96.8 \%$ - 99.8\% recovery (Table 4). Samples required less than 5 min to be digested fully, slight variation of $(<1 \%-2 \%)$ with respect to mean values of each element was observed with relative standard deviation (RSD) $<2 \%$.

Table 4. Determination of $\mathrm{Ca}$ and $\mathrm{Pb}$ in certified samples by microwave digestion method $(\mathrm{N}=6)$.

\begin{tabular}{|c|c|c|c|c|}
\hline Elements & $\begin{array}{l}\text { Certified } \\
\text { values }\end{array}$ & $\begin{array}{c}\text { MWD } \\
\text { Mean } \pm \text { SD }\end{array}$ & (\%) Recovery & $\begin{array}{l}\text { Paired } t \text {-test } \mathrm{t}^{\mathrm{a}} \\
\mathrm{t}^{\text {Experimental }}\end{array}$ \\
\hline \multicolumn{5}{|c|}{ Certified sample of whole blood $(\mu \mathrm{g} / \mathrm{l})$} \\
\hline $\mathrm{Ca}(\mathrm{mg} / \mathrm{l})$ & $14.7 \pm 0.3$ & $\begin{array}{c}14.65 \pm 1.2 \\
\quad(8.19)\end{array}$ & 99.7 & 0.985 \\
\hline $\mathrm{Pb}(\mu \mathrm{g} / \mathrm{l})$ & $105 \pm 24$ & $\begin{array}{c}104.8 \pm 7.3 \\
(6.96)\end{array}$ & 96.8 & 0.0012 \\
\hline \multicolumn{5}{|c|}{ Certified sample of human hair $(\mu \mathrm{g} / \mathrm{g})$} \\
\hline $\mathrm{Ca}$ & $1560 \pm 40^{c}$ & $\begin{array}{c}1556.5 \pm 55.2 \\
(3.54)\end{array}$ & 99.8 & 0.883 \\
\hline $\mathrm{Pb}$ & $33.0 \pm 1.2$ & $\begin{array}{c}32.56 \pm 1.18 \\
\quad(3.62)\end{array}$ & 98.7 & 0.095 \\
\hline
\end{tabular}

${ }^{\text {aPaired }} \mathrm{t}$-test between certified values vs. found values, degree of freedom $(n-1)=5 . \mathrm{t}_{\text {Critical }}$ at $95 \%$ confidence limit $=2.57$. ${ }^{\mathrm{b}}$ Values in parenthesis RSD. ${ }^{*} \mathrm{mg} / \mathrm{l}$. 


\section{Results}

\subsection{Biochemical Parameters of Employees of Lakhra Coal Mining Field}

The obtained data regarding biochemical parameters showed that the serum ferritin, hemoglobin, hematocrit, red blood count and creatinine clearance levels found to be lower in the serum samples of indoor and outdoor workers of five sub zonal areas of Lakhra coalfield as compare to non-exposed referent subjects of two age groups (18 - 35 and $36-55$ years) ( $p<0.01)$. Whilst ESR and NAG levels in workers' serum samples were found to be higher $(\mathrm{p}<0.003)$.

\subsection{Calcium and Lead Concentrations in the Biological Samples of Coal Mining Areas Workers}

In the present study, the biological samples (scalp hair, blood) collected from the indoor and outdoor workers of five different zones of the Lakhra coal mining area. The statistical differences between the results of the $\mathrm{Ca}$ and $\mathrm{Pb}$ in biological samples of two categories of five different zones of Lakhra coal mining area with exposed and unexposed subjects were analyzed by multivariate statistical analysis ANOVA, using the $\mathrm{p}$-value as a discrimination factor.

In scalp hair samples of male referent subjects, Ca concentrations were found to be higher \{confidence limit (CI: $2800-3040 \mu \mathrm{g} / \mathrm{g}$ ) and (CI: $2600-2780 \mu \mathrm{g} / \mathrm{g}$ ) than those $\mathrm{Ca}$ values observed in the scalp hair samples of outdoor and indoor workers of coal mining areas $\{(\mathrm{CI}: 1382-1575 \mu \mathrm{g} / \mathrm{g})$ and (CI: 1285 - $1465 \mu \mathrm{g} / \mathrm{g}$ ) $\}$ and $\{(\mathrm{CI}: 1290-1460 \mu \mathrm{g} / \mathrm{g})(\mathrm{CI}: 995-1260 \mu \mathrm{g} / \mathrm{g})\}(\mathrm{p}<0.001)$ in age group of 18 - 35 and 36 - 55 years, respectively (Table 5). However, the reverse pattern was observed in the case of $\mathrm{Pb}$ (Table 5).

Table 5. Calcium and lead contents in biological (scalp hair and blood) samples of mining areas workers.

\begin{tabular}{|c|c|c|c|c|c|c|c|}
\hline \multirow{2}{*}{ Mining Areas workers } & \multirow{2}{*}{ Age groups } & \multirow{2}{*}{ Referents } & \multicolumn{5}{|c|}{ Workers } \\
\hline & & & PMDC & LCDC & ICD & $\mathrm{HCM}$ & $\mathrm{BCM}$ \\
\hline \multicolumn{8}{|c|}{ Scalp hair $(\mu g / g)$} \\
\hline \multirow{2}{*}{ Outdoor workers } & \multirow{5}{*}{$18-35$} & $2903 \pm 212$ & $1463 \pm 119$ & $1447 \pm 81.8$ & $1435 \pm 114$ & $1517 \pm 128$ & $1467 \pm 80.6$ \\
\hline & & $2795-3050$ & $1392-1520$ & $1402-1480$ & $1382-1495$ & $1450-1575$ & $1420-1505$ \\
\hline p-values & & $\ldots \ldots$. & 0.001 & 0.001 & 0.001 & 0.003 & 0.001 \\
\hline \multirow{2}{*}{ Indoor workers } & & & $1390 \pm 135$ & $1375 \pm 110$ & $1340 \pm 95.7$ & $1350 \pm 130$ & $1364 \pm 102$ \\
\hline & & - & $1320-1460$ & $1305-1430$ & $1290-1396$ & $1290-1450$ & $1310-1425$ \\
\hline $\mathrm{p}$-values & & $\ldots \ldots$ & 0.001 & 0.001 & 0.001 & 0.001 & 0.001 \\
\hline Outdoor workers & \multirow{4}{*}{$36-55$} & $2615-2750$ & $1350-1465$ & $1305-1420$ & $1285-1370$ & $1290-1420$ & $1325-1460$ \\
\hline p-values & & $\ldots \ldots$ & 0.001 & 0.001 & 0.001 & 0.001 & 0.001 \\
\hline \multirow{2}{*}{ Indoor workers } & & & $1180 \pm 148$ & $1080 \pm 182$ & $1137 \pm 147$ & $1165 \pm 128$ & $1172 \pm 101$ \\
\hline & & - & $1110-1260$ & $995-1160$ & $1060-1210$ & $1100-1230$ & $1120-1234$ \\
\hline p-values & & $\ldots \ldots$ & 0.001 & 0.001 & 0.001 & 0.001 & 0.001 \\
\hline
\end{tabular}




\section{Continued}

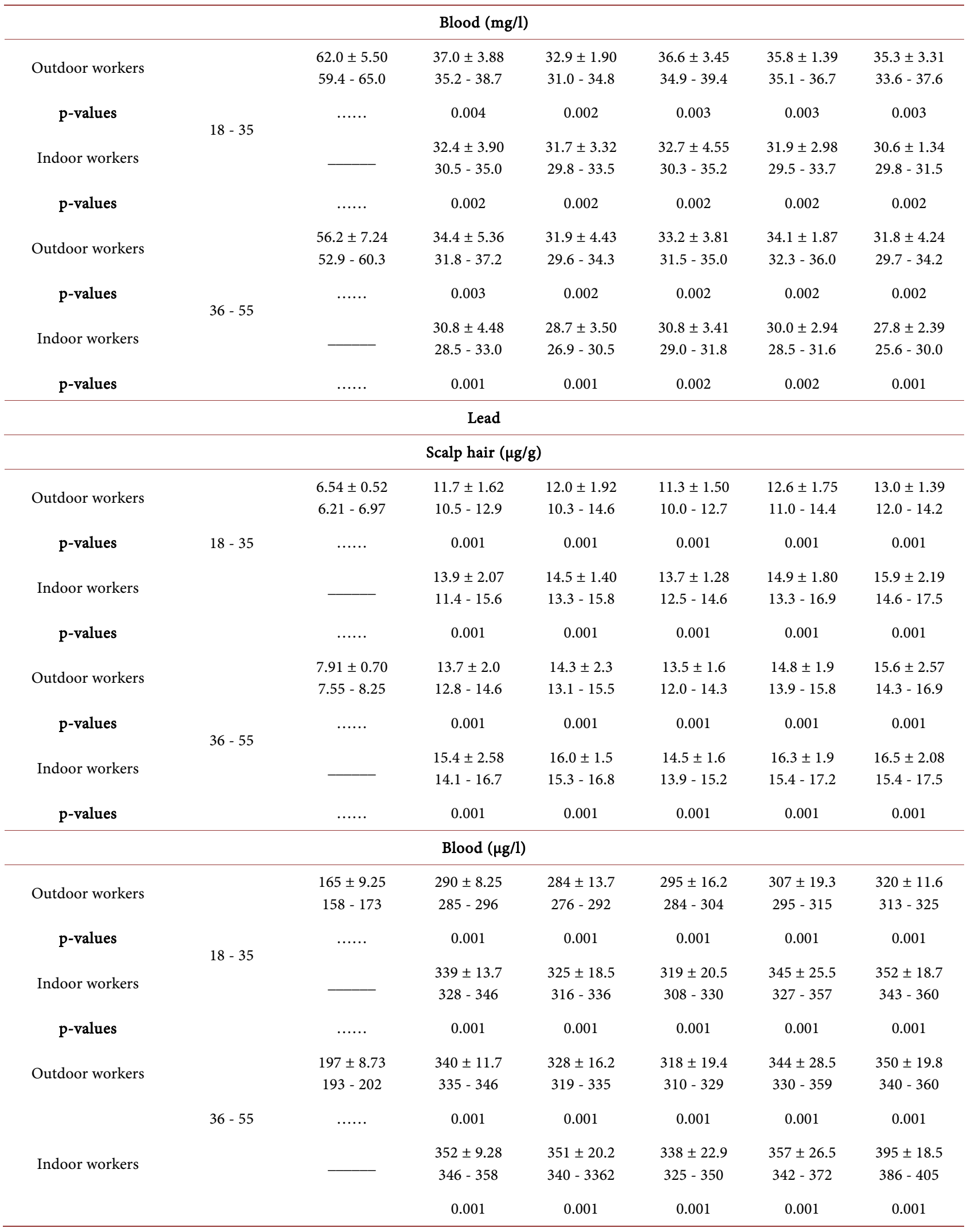

Keywords: Lakhra coal development company (LCDC), Hashim coal mine (HCM), Indus coal mine (ICM), Bismillah coal mine (BCM), and Pakistan mine development company (PMDC). 
The Ca concentrations in blood samples of male outdoor referent subjects, age ranged 18 - 35 and 36 - 60 years was found to be higher (CI: 59.0 - 64.7) and (CI: $53.0-60.8) \mathrm{mg} / \mathrm{L}$ as compared to male outdoor and indoor workers of coal mining areas $\{(\mathrm{CI}: 31.0$ - 39.4), (CI: 29.6 - 37.2) $\} \mathrm{mg} / \mathrm{l}$ and $\{(\mathrm{CI}: 29.5$ - 35.0) \& (CI: 25.6 - 33.0) $\} \mathrm{mg} / \mathrm{l}$ in age groups 18 - 35 and 36 - 55 years, respectively (Table 5). Although blood $\mathrm{Pb}$ levels in male outdoor referent subjects age ranged 18 - 35 and 36 - 60 years found to be lower (CI: 160 - 175) and (CI: 190 - 205) $\mu \mathrm{g} / \mathrm{L}$ as compared to male outdoor and indoor workers of coal mining areas in age groups 18 - 35 and 36 - 60 years, respectively (Table 5).

Student $\mathrm{t}$-test (unpaired) calculated between all studied groups at different probabilities. The calculated $t$-value exceeds to the critical $t$-value at $95 \%$ confidence intervals, which indicated that the difference among means values of $\mathrm{Pb}$ and $\mathrm{Ca}$ in referents and outdoor and indoor coal mining area workers of both age groups exhibited significant differences $(\mathrm{p}<0.001)$.

\section{Discussion}

This research study gives information on essential trace and toxic elemental level in biological (scalp hair and blood) samples, gained from outdoor and indoor workers of coal mining areas of five different zone sufferers and those of non-diseases subjects of age matched groups having two different age groups (18 - 35 and 36 - 55) years.

Observational epidemiological examinations, on the basis of dietary Ca consumption in various populaces and age groups on various parameters, don't permit the distinguishing proof of edge estimations of Ca levels that lead to decreases in these parameters [5]. Calcium assumes numerous significant roles in the discharge, synthesis and receptor responsiveness to synapses in the upkeep and end of action potential, and in the neuronal memory of past incitement [5].

Lead is a neurotoxicant and has the capacity of meddling with numerous biochemical occasions in cells all through the body and can create a wide range of changes in numerous organs [15] [16]. Roux et al. (2005) have stated that $\mathrm{Pb}$ has no physiological capacity and is conceivably dangerous, and generally scattered in the earth since the start of metallurgy [16]. The $\mathrm{Pb}$ is one of the significant ecological need pollutants, has poisonous and collective impact. Lead cannot biodegradable and its constant use has sullied air, soil, and water. Berkowitz et al., 2006 stated that $\mathrm{Pb}$ has lethal effects on people of all ages gathering for the most part kids are antagonistically influenced [17]. Humans are exposed to $\mathrm{Pb}$ through absorption from the air in the earth around and diet admission [17]. It is known for its aggregation in some delicate tissues like cerebrum, kidneys, liver and bones [17]. The $\mathrm{Pb}$ is lethal to humans inhibiting many systems in their bodies such as nervous, cardiovascular, hemopoietic, reproductive and urinary systems [18]. The $\mathrm{Pb}$ is liable for social imperfections, hindrance of mental advancement and knowledge [19]. High pollution levels of $\mathrm{Pb}$ may be because of its compound security and industriousness properties for quite a long while [20].

Toxic metals are renowned poisons of water and soil. The lethal impacts of them 
are answerable for the huge research about the effect on people, and other living life forms. Some of them are considered to have high poisonous potential because of their long time amassing in the collections of living things. It was immensely studied that, dirt, air and water are in effect widely tainted because of their utilization in various innovations, shades, mining, manures, and their evolvement during consuming petroleum derivatives and cremation of waste [21].

The trace components present in coal straightforwardly or in a roundabout way cause air contamination. The effect of trace components on human wellbeing can't be totally named as dangerous or cancer-causing, as impacts of follow metal rely on the life form, measurements and compound structure. Various trace elements are significant and basic for the digestion of the man, yet might be poisonous in the case that they are in abundance sum required by the body. These have been ordered by level of concern dependent on realized antagonistic health impacts or on account of their abundance in coal [22]. The concentration, circulation and methods of event of metals in coal rely mostly on the geographical variables like depositional conditions, the cooperation between the natural matter and basinal liquids, sidiment digenesis and semi inactive volcanic information sources [23].

The release of the trace elements from coal as vapor or fine particles during combustion causes potential toxicity to plants, animals and humans and pollution to ecological environment under certain conditions and concentrations. The formation of the technology for the coal utilization units requires the understanding of their occurrence in coal, their behavior during and prior to combustion and their form in the stack gas [24]. Because of their potential hazardous effects, toxic metals are given particular consideration among various environmental pollutants [25].

Toxic metals are renowned pollutants of soil and water. The toxic effects of them are responsible for the immense research about the impact on humans, and other living organisms. Some of them are considered to have high toxic potential due to their long time accumulation in the bodies of living things. It was immensely studied that, soil, air and water are being extensively contaminated due to their usage in different technologies, pigments, mining, fertilizers, and their evolvement during burning fossil fuels and incineration of waste [25].

The trace elements present in coal directly or indirectly cause air pollution. The impact of trace elements on human health can't be absolutely termed as toxic or carcinogenic, as effects of trace metal depends upon the organism, dosage and chemical form. Many trace elements are, in fact, essential for the metabolism of the man, but may be toxic if they are in excess amount required by the body. These have been classified by level of concern based on known adverse health effects or because of their abundances in coal [26].

The concentration, distribution and modes of occurrence of metals in coal depend mainly upon the geological factors like depositional environments, the interaction between the organic matter and basinal fluids, sediment digenesis and semi-sedentary volcanic inputs (Islam et al., 2018). The release of the trace 
elements from coal as vapor or fine particles during combustion causes potential toxicity to plants, animals and humans and pollution to ecological environment under certain conditions and concentrations [27]. The formation of the technology for the coal utilization units requires the understanding of their occurrence in coal, their behavior during and prior to combustion and their form in the stack gas [28]. Because of their potential hazardous effects, toxic metals are given particular consideration among various environmental pollutants [29].

It was reported in previous study that toxic elements (Lead) have antagonistic effect with essential trace elements, such as zinc $(\mathrm{Zn})$ and calcium (Ca). It was investigated that the accumulation of $\mathrm{Cd}$ in the human body may replace $\mathrm{Zn}$ in the arteries, which contributes to the arteries becoming brittle and inflexible. Once the arteries become inflamed and brittle, the body may coat them with $\mathrm{Ca}$ and fatty plaques to prevent their rupture [30]. This plaque unfortunately reduces the interior diameter of the arteries, resulting in more pressure being required to force the blood through the smaller diameter arteries, which in turn raises blood pressure [30]. It was reported in previous study that toxic elements have antagonistic effect with essential trace elements, such as $\mathrm{Zn}$ and calcium (Ca). It was investigated that the accumulation of $\mathrm{Cd}$ in the human body may replace $\mathrm{Zn}$ in the arteries, which contributes to the arteries becoming brittle and inflexible. Once the arteries become inflamed and brittle, the body may coat them with $\mathrm{Ca}$ and fatty plaques to prevent their rupture [30]. This plaque unfortunately reduces the interior diameter of the arteries, resulting in more pressure being required to force the blood through the smaller diameter arteries, which in turn raises blood pressure [30].

Correlation of Biochemical Parameters with zinc levels in biological samples of workers of Lakhra Coal Mining Field

The correlation ( $r$ ) between Ca concentration in biological samples (scalp hair and blood) vs biochemical parameters (Serum ferritin, Hemoglobin, Hematocrit, RBC, SBP, DBP, ESR, creatinine clearance and NAG) of referents and indoor and outdoor workers of five different sub zones of coal mining area, age ranged (18 - 55 years) was observed from resulted data that correlation (r) of Ca concentration in biological samples Vs biochemical parameters (Serum ferritin, Hemoglobin, Hematocrit, RBC, creatinine clearance) of non-exposed referents shows $(r=0.46-0.59)$ whilst with the biological samples of employees of five sub zone of coal mining area, the correlation were found to be in the range of ( $\mathrm{r}$ $=0.0 .09-0.23)$. The correlation ( $\mathrm{r}$ ) values of Ca level in biological samples of referents with biochemical parameters (systolic and disystolic BP) of referents shows ( $\mathrm{r}=0.34-0.43$ ) while with the workers's SBP and DBP, the correlation was found to be $(r=0.50-0.73)$ of both age groups. The correlation $(r)$ values between biological samples Ca concentration vs biochemical parameter (ESR and NAG) of referents shows $(r=0.0 .07-0.11)$, whilst in the workers of indoor and outdoor five sub zonal area of coal mining field, the correlation was found to be in the range of $(r=0.0 .51-0.83)$ of both age groups. 
Table 6. $\mathrm{Ca} / \mathrm{Pb}$ mole ratio in biological samples of referents and workers of different zone of coal mining industry.

\begin{tabular}{|c|c|c|c|c|c|c|c|}
\hline \multirow{2}{*}{$\begin{array}{l}\text { Mining Areas } \\
\text { workers }\end{array}$} & \multirow{2}{*}{$\begin{array}{l}\text { Age } \\
\text { groups }\end{array}$} & \multirow{2}{*}{ Referents } & \multicolumn{5}{|c|}{ Workers } \\
\hline & & & PMDC & LCDC & ICD & $\mathrm{HCM}$ & $\mathrm{BCM}$ \\
\hline \multicolumn{8}{|c|}{ Calcium/Lead Mole ratio } \\
\hline \multicolumn{8}{|c|}{ Scalp hair } \\
\hline Outdoor workers & & 0.00131 & 0.00154 & 0.0016 & 0.00152 & 0.001603 & 0.001711 \\
\hline Indoor workers & $18-35$ & -----.--- & 0.00193 & 0.00204 & 0.001974 & 0.002131 & 0.00225 \\
\hline Outdoor workers & $36-55$ & 0.00172 & 0.00188 & 0.00202 & 0.001957 & 0.002112 & 0.00217 \\
\hline Indoor workers & $36-53$ & & 0.00252 & 0.00286 & 0.002462 & 0.002701 & 0.002718 \\
\hline \multicolumn{8}{|c|}{ Blood } \\
\hline Outdoor workers & & 0.00155 & 0.00151 & 0.00167 & 0.001556 & 0.001655 & 0.00175 \\
\hline Indoor workers & $10-3$ & - & 0.00202 & 0.00198 & 0.001883 & 0.002088 & 0.002221 \\
\hline Outdoor workers & $36-55$ & 0.00204 & 0.00191 & 0.00198 & 0.001849 & 0.001947 & 0.00215 \\
\hline Indoor workers & & 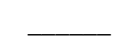 & 0.00221 & 0.00236 & 0.002119 & 0.002297 & 0.002743 \\
\hline
\end{tabular}

Keywords: Lakhra coal development company (LCDC), Hashim coal mine (HCM), Indus coal mine (ICM), Bismillah coal mine (BCM), Pakistan mine development company (PMDC).

The $\mathrm{Ca} / \mathrm{Pb}$ mole ratio was also found to be higher in the scalp hair and blood samples of outdoor and indoor male coal mining workers of both age groups (Table 6).

\section{Conclusions}

The concentration of toxic element $(\mathrm{Pb})$ was found to be higher in biological samples of outdoor and indoor workers of five different sub sections of Lakhra coal mining area, whilst essential element ( $\mathrm{Ca}$ ) was found to be lower than nonexposed referent subjects. The results show that in mining areas, the workers assigned to the different sections are indeed exposed to TEs, presenting significantly elevated levels in both biological samples, when compared to normal unexposed referents. Continuous monitoring should be done for the TEs exposure to take the workers' health into account. This suggests the need for immediate improvement of workplace ventilation and industrial hygiene practices.

These reported results suggest due to high exposure of toxic metals levels, workers faced different disorders such as stomach disorder, kidney disorder, osteoporosis, weak immune function, diarrhea, delayed sexual maturation, hypogonadism in male and some neurological disorders having which were closely monitored during the process of workers. Even though coal is available in abundance, its quality is poor. Most coal available is of lowest quality, and in bulk, which is mostly used by the energy sector, whereas, some coal mines are owned by private companies, which are not interested to invest in developing methods for improving the coal quality. Levels of understudied found in biological samples of PMDC, LCDC, ICD, HCM and BCM showed different exposure extent. 
The results show that in coal mining area workers assigned to the different five sub-zones of coal mining areas are indeed exposed to lead $(\mathrm{Pb})$, presenting significantly elevated levels in both biological samples when compared to normal unexposed referents. It is necessary to be continually monitored to evaluate the potential risks of long-term exposure and to protect workers' health.

\section{Conflicts of Interest}

The authors declare no conflicts of interest regarding the publication of this paper.

\section{References}

[1] Mineral Deposits of Pakistan (PDF). pakboi.gov.pk. 2012.

[2] Spooner, A.M. (2015) What Is the Environmental Impact of Mining and Burning Coal?

https://dummies.com/education/science/environmental-science/what-is-the-enviro nmentalimpact-of-mining-and-burning-coal

[3] Ortega-Larrocea, M.P., Xoconostle-Cazares, B., Maldonado-Mendoza, I.E., et al. (2010) Plant and Fungal Biodiversity from Metal Mine Wastes under Remediation at Zimapan, Hidalgo, Mexico. Environmental Pollution, 158, 1922-1931. https://doi.org/10.1016/j.envpol.2009.10.034

[4] Li, F., Chong, Z.Z. and Maiese, K. (2005) Vital Elements of the Wnt-Frizzled Signaling Pathway in the Nervous System. Current Neurovascular Research, 2, 331-340. https://doi.org/10.2174/156720205774322557

[5] Afridi, H.I., Talpur, F.N., Kazi, T.G., et al. (2015) Estimation of Calcium, Magnesium, Cadmium, and Lead in Biological Samples from Paralyzed Quality Control and Production Steel Mill Workers. Environmental Monitoring and Assessment, 187, 350. https://doi.org/10.1007/s10661-015-4517-3

[6] Faqi, L., Zhao, Z.C. and Kenneth, M. (2005) Vital Elements of the Wnt-Frizzled Signaling Pathway in the Nervous System. Current Neurovascular Research, 2, 331-340. https://doi.org/10.2174/156720205774322557

[7] Fowler, B.A., Yamauchi, H., Conner, E.A., et al. (1993) Cancer Risks for Humans from Exposure to Semiconductor Metals. Scandinavian Journal of Work, Environment \& Health, 19, 101-103.

[8] Kazi, T.G., Afridi, H.I., Kazi, N., et al. (2008) Distribution of Zinc, Copper and Iron in Biological Samples of Pakistani Myocardial Infarction (1st, 2nd and 3rd Heart Attack) Patients and Controls. Clinica Chimica Acta, 389, 114-119. https://doi.org/10.1016/j.cca.2007.12.004

[9] Boutron, C.F. (1991) Decrease in Anthropogenic Lead, Cadmium and Zinc in Greenland Snows since the Late 1960s. Nature, 353, 153-156. https://doi.org/10.1038/353153a0

[10] ATSDR (2005) Toxicological Profile for Lead. Draft for Public Comment.

[11] Centers for Disease Control (1992) Preventing Lead Poisoning in Young Children. DHHS Publication No. (PHS/CDC), USA Department of Health and Human Services, Centers for Disease Control, Atlanta, 633-627.

[12] Saraymen, R., Soylak, M. and Narin, I. (1998) Serum Cadmium Levels of People Living in Kayseri-Belsin Region, Turkey. Fresenius Environmental Bulletin, 7, 403-405.

[13] Soylak, M., Saraymen, R. and Dogan, M. (1995) Investigation of Lead, Chromium, 
Cobalt and Molybdenum Concentrations in Hair Samples Collected from Diabetic-Patients. Fresenius Environmental Bulletin, 4, 485-490.

[14] International Labor Organization (1999) Convention Concerning the Prohibition and Immediate Action for the Elimination of the Worst Forms of Child Labour (No. 182).

[15] Berkowitz, Z., Price-Green, B. and Kaye, W.E. (2006) Lead Exposure and Birth Outcomes in Five Communities in Shoshone County, Idaho. International Journal of Hygiene and Environmental Health, 209, 123-132. https://doi.org/10.1016/j.ijheh.2005.11.001

[16] Le Roux, G., Aubert, D., Stille, P., et al. (2005) Recent Atmospheric Pb Deposition at a Rural Site in Southern Germany Assessed Using a Peat Core and Snowpack, and Comparison with Other Archives. Atmospheric Environment, 39, 6790-6801. https://doi.org/10.1016/j.atmosenv.2005.07.026

[17] Lee, B.K., Ahn, J., Kim, N.S., et al. (2016) Association of Blood Pressure with Exposure to Lead and Cadmium: Analysis of Data from the 2008-2013 Korean National Health and Nutrition Examination Survey. Biological Trace Element Research, 174, 40-51. https://doi.org/10.1007/s12011-016-0699-y

[18] Telišman, S., Čolak, B., Pizent, A., et al. (2007) Reproductive Toxicity of Low-Level Lead Exposure in Men. Environmental Research, 105, 256-266. https://doi.org/10.1016/j.envres.2007.05.011

[19] Papanikolaou, N.C., Hatzidaki, E.G., Belivanis, S., et al. (2005) Lead Toxicity Update. A Brief Review. Medical Science Monitor, 11, RA329-RA336.

[20] Small, M.J., Nunn, A.B., Forslund, B.L., et al. (1995) Source Attribution of Elevated Residential Soil Lead near a Battery Recycling Site. Environmental Science \& Technology, 29, 883-895. https://doi.org/10.1021/es00004a008

[21] Cheepurupalli, N.R., Radha, B.A., et al. (2015) Chemical Characteristics and Trace Element Concentration of Non Coking Coals from Talcher Coal Fields, Orissa, India. Science, Technology and Arts Research Journal, 4, 197-205. https://doi.org/10.4314/star.v4i3.31

[22] Shao, L., Jones, T., Gayer, R., et al. (2003) Petrology and Geochemistry of the High-Sulphur Coals from the Upper Permian Carbonate Coal Measures in the Heshan Coalfield, Southern China. International Journal of Coal Geology, 55, 1-26. https://doi.org/10.1016/S0166-5162(03)00031-4

[23] Dai, S., Li, D., Chou, C., et al. (2008) Mineralogy and Geochemistry of Boehmite-Rich Coals: New Insights from the Haerwusu Surface Mine, Jungar Coalfield, Inner Mongolia, China. International Journal of Coal Geology, 74, 185-202. https://doi.org/10.1016/j.coal.2008.01.001

[24] Kedziorek, M.A., Dupuy, A., Bourg, A.C., et al. (1998) Leaching of Cd and Pb from a Polluted Soil during the Percolation of EDTA: Laboratory Column Experiments Modeled with a Non-Equilibrium Solubilization Step. Environmental Science \& Technology, 32, 1609-1614. https://doi.org/10.1021/es970708m

[25] Othmer, K. (2003) Encyclopedia of Chemical Technology. Fourth Edition, John Wiley \& Sons, Hoboken.

[26] Ali, H., Khan, E. and Ilahi, I. (2019) Environmental Chemistry and Ecotoxicology of Hazardous Heavy Metals: Environmental Persistence, Toxicity, and Bioaccumulation. Journal of Chemistry, 2019, Article ID: 6730305. https://doi.org/10.1155/2019/6730305

[27] Islam, M.S., Proshad, R. and Ahmed, S. (2018) Ecological Risk of Heavy Metals in Sediment of an Urban River in Bangladesh. Human and Ecological Risk Assess- 
ment, 24, 699-720. https://doi.org/10.1080/10807039.2017.1397499

[28] Tian, H.Z., Lu, L., Hao, J.M., et al. (2013) A Review of Key Hazardous Trace Elements in Chinese Coals: Abundance, Occurrence, Behavior during Coal Combustion and Their Environmental Impacts. Energy \& Fuels, 27, 601-614. https://doi.org/10.1021/ef3017305

[29] Zahra, A., Hashmi, M.Z., Malik, R.N., et al. (2014) Enrichment and Geo-Accumulation of Heavy Metals and Risk Assessment of Sediments of the Kurang Nallah-Feeding Tributary of the Rawal Lake Reservoir, Pakistan. Science of the Total Environment, 470-471, 925-933. https://doi.org/10.1016/j.scitotenv.2013.10.017

[30] Navas-Acien, A., Selvin, E., Sharrett, A.R., Calderon-Aranda, E., Silbergeld, E., Guallar, E., et al. (2014) Lead Cadmium, Smoking, and Increased Risk of Peripheral Arterial Disease. Circulation, 109, 3196-3201.

https://doi.org/10.1161/01.CIR.0000130848.18636.B2 